\title{
Optimal Dispatch through Deterministic Dual Objective Particle Swarm Optimization
}

\author{
A.T. Rajadurai ${ }^{1}$, N.R.Naharaj ${ }^{2}$, Dr.A.Soundarrajan ${ }^{3}$ \\ Assistant Professor - Department of EEE, RVS College of Engineering and Technology, Coimbatore, India ${ }^{1}$ \\ Associate Professor - Department of EEE, RVS College of Engineering and Technology, Coimbatore, India ${ }^{2}$ \\ Associate Professor - Department of EEE, PSG College of Technology, Coimbatore, India ${ }^{3}$
}

\begin{abstract}
The operation of generating units to generate energy at reduced cost to reliably serve consumers, recognizing any operational restrictions of generation and transmission facilities is called as Economic Dispatch(ED).In the present paper, an evolutionary modified Deterministic Particle Swarm Optimization (DPSO) is applied for Environmental and Economic Power Dispatch (EED) problem to find fast and efficient solutions for IEEE 14 and 30 bus systems. In such a way, proposed algorithms reduce the total expenditure task of the generating units and improve the computational efficiency. The feasibility of the proposed DPSO based algorithm is demonstrated for two power system test cases consisting of IEEE 14 bus 3-generator system and 30 bus 6-generator system. The results obtained are compared to previous PSO, GA.
\end{abstract}

Keywords - Economic Dispatch, Deterministic Particle Swarm Optimization, Operational Limits, Power System

\section{INTRODUCTION}

In practical, power systems which are able to supply a bounded range of electrical load demand, optimizing the operation expenses of the generation units is very significant from an economic point of view. It can be done by proper scheduling of each generating units which is commonly called as Economic dispatch. The conservative technique includes lambda iteration method, base point and participation factor method, gradient method, etc. However, these conventional dispatch algorithms necessitate the incremental cost curves to be monotonically rising or piece-wise linear and are highly sensitive in selecting the initial point and frequently converge to local optimal solution or diverge altogether. Hence, Economic Dispatch (ED) techniques are used to determine a condition with the lowest generation costs. The load demand, transmission power losses and generation cost coefficients are the factors must be taken into account for any ED technique. Newton based algorithms have a problem in handling a large number of inequality constraints. Linear programming methods are fast and trustworthy, but the main drawback is linked with the piecewise linear cost approximation. Non linear encoding technique has a problem of convergence and algorithm complexity.

Methods such as Simulated Annealing (SA) [1], Genetic Algorithms (GA) and Evolutionary Programming (EP) have the benefit in searching the solution space more thoroughly, and avoiding premature convergence to local minima. However, the main complexity is their sensitivity to the choice of parameters, such as temperature in SA, the cross over and mutation possibilities in GA [2,3] and scaling aspect in EP. To overcome above difficulties PSO is employed.
PSO is originally attributed to Kennedy, Eberhart and Shi and was first intended for simulating social behavior, as a stylized illustration of the movement of organisms in a bird flock or fish school. The algorithm is trouble-free to understand and it was observed to be performing optimization. PSO is one of the modern heuristic algorithms suitable to solve large-scale nonconvex optimization problems. It is a population-based search algorithm and searches in parallel using a group of particles. PSO is a computational method that optimizes a problem by iteratively trying to improve the solution with regard to a given measure of excellence [4]. PSO optimizes a problem by having a population of candidate solutions, here dubbed particles, and moving these particles around in the search according to simple mathematical formulae over the particle's position and velocity. Each particle's progress is influenced by its local best known position but, is also directed towards the best known positions in the searchspace, which are updated as superior positions are found by other particles. This is expected to travel the swarm in the direction of the best solutions. PSO can therefore also be used on optimization problems that are partially rough, noisy, modify over time, etc. PSO technique seems to be sensitive to the deviation of weights and factors; hence dissimilar values for parameter have been set to obtain out how different factors and Parameters can influence the swarm performance. However, the results presented only belong to the best set of parameters which guide the swarm to the best possible place but the most important difficulty in this method is computational efficiency, which is very poor. Thus to improve the computational efficiency, an evolutionary modified Deterministic particle swarm optimization (DPSO) is applied for Economic Dispatch (ED) problem to find fast and efficient solutions. 


\section{Formulation of Economic Dispatch Problem}

\section{A. Multi-OBJective OPTIMIZATION}

Real-world optimization problems often need to deal with two or more conflicting objectives, and such Multiobjective optimization aims to find a family of global-optimal solutions in which none of these solutions can outperform any other for all objectives. In mathematical terms, the global optimization can be formulated as

$$
\min F=\sum_{i=1}^{N} F_{i}\left(P_{i}\right)
$$

The fundamental outline of PSO is composed by group particles, where each particle corresponds to a possible solution of the problem. Each particle maps the quality of a solution, i.e., the position of one particle represents exactly the value of quality of a solution. In addition, particles move in the interior search space reaching new positions. After some iteration, particles tend to a global optimum based on two basic components: the cognitive factor and the social factor.

The first one considers the best position already initiate by the particle itself $\left(\mathrm{p}_{\text {best }}\right)$. The second one use the best position attained by all the particles of the swarm ( $\left.g_{\text {best }}\right)$ in order to guide the swarm to a common spot in the search space. Based on these two information components, each particle modernizes its own velocity. The velocity is a vector that directs the particle to the next position.

The solutions which are nondominated within entire feasible search space are known as global-optimal solutions. The following are three basic quality measure criteria for evaluating the $\mathrm{g}_{\text {best }}$ resulted from various Multiobjective optimization algorithms [5]

1) The distance of the resulting nondominated $g_{\text {best }}$ set to the true $g_{\text {best }}$ should be minimized.

2) The g $g_{\text {best }}$ should be as uniformly distributed as possible.

3) The extent of the obtained nondominated $g_{\text {best }}$ in objective space should be maximized.

\section{B. DPSO OBJECTIVES $[6,7]$}

1) Economic Objective: The economic objective of DPSO is to minimize the total generation cost. The fuel cost of units with non-convexity caused by valve-point effects is modeled as the ripple curve, and the total fuel cost in $(\$ / \mathrm{h})$ can be expressed with quadratic functions and sine components as

$$
F_{i}\left(P_{i}\right)=a_{i}+b_{i} P_{i}+c_{i} P_{i}^{2}+\operatorname{abs}\left(e_{i} \sin \left(f_{i}\left(P_{i \min }-P_{i}\right)\right)\right)
$$

2) Emission Objective: The intention of emission dispatch is to reduce the atmospheric pollutants due to fossil-fueled thermal units, such as sulfur dioxides and nitrogen oxides, etc. The total emission in (ton/h) can be represented as

$$
E_{i}\left(P_{i}\right)=\alpha_{i}+\beta_{i} P_{i}+\gamma_{i} P_{i}^{2}+\xi_{i} \exp \left(\lambda \times P_{i}\right)
$$

3) Transmission Loss Objective: The aim of energy-saving generation dispatch is to minimize power transmission losses, and the minimization of power loss in transmission lines can therefore be used as an objective of DPSO. The solution involves the calculation of load flow problem, which can be readily solved using Newton-Raphson method

$$
P_{\text {Loss }}=\sum_{i=1}^{n g} \sum_{j=1}^{n g} P_{i} B_{i j} P_{j}
$$

\section{DPSO CONSTRAINTS [8]}

1. Power Balance Constraint: Since the total power outputs of generators must equal to the sum of total load demand $\mathrm{P}_{\mathrm{D}}$ plus power loss $\mathrm{P}_{\mathrm{LOSS}}$, after the load flow calculation the active power output of the slack generator should be reassigned to satisfy the equality constraint

$$
\sum_{i=1}^{N_{G}} P_{G i}-P_{D}-P_{\text {Loss }}=0
$$

2. Generation Constraints: The active power output of each generator should be within its lower and upper limits. For generator $\mathrm{i}$ with NPi prohibited operating zones (POZs), its feasible operating zones can be described as a disjoint nonconvex set

$$
\begin{aligned}
& \mathrm{P}_{\mathrm{Gi}, \min } \leq \mathrm{P}_{\mathrm{Gi}} \leq \mathrm{P}_{\mathrm{Gi}(1), \mathrm{lb}} \\
& \mathrm{P}_{\mathrm{Gi}(\mathrm{j}-1), \mathrm{ub}} \leq \mathrm{P}_{\mathrm{Gi}} \leq \mathrm{P}_{\mathrm{Gi}(\mathrm{j}), \mathrm{lb}}
\end{aligned}
$$$$
\text { (6) }
$$$$
\mathrm{j}=2,3, \ldots \mathrm{NP} \quad \mathrm{i}
$$

$$
\mathrm{P}_{\mathrm{Gi}(\mathrm{j}) \text {,ub }} \leq \mathrm{P}_{\mathrm{Gi}} \leq \mathrm{P}_{\mathrm{Gi}, \max } \quad \mathrm{j}=\mathrm{NP}_{\mathrm{i}}
$$

The above limitations are essentially control parameters, which are necessary to be within their limits for satisfactory operation of the power system. Although the primary concern is minimization of objective functions, due to operational limitations these constraints must be incorporated in the study.

\section{OVerview Of Particle SWarm Optimization}

PSO uses a vectorized search space where every particle in search space offers a solution to the problem. It is swarm intelligence based algorithm which uses location and velocity of the particles to estimate them using a fitness function or so called objective function. For each particle, the best position obtained during its flight in the problem search space referred to as "personal best particle" $\left(\mathrm{P}_{\text {best }}\right)$. For minimization mission, the position having the smallest function value is regarded as having the highest fitness. 
Also, the finest position among all $\mathrm{P}_{\text {best }}$ positions is referred to as global best $\left(\mathrm{G}_{\text {best }}\right)$. At each iteration the velocity of each particle is modified using the existing velocity and its distance from $\mathrm{P}_{\text {best }}$ and $\mathrm{G}_{\text {best }}$ are defined by equation $(7)[9,10]$.

$$
V_{i}^{k+1}=W \times V_{i}^{k}+c_{1} \times r_{1}\left(\text { Gbest } t_{i}^{k}-X_{i}^{k}\right)+c_{2} \times r_{2}\left(\text { Pbest } t_{i}^{k}-X_{i}^{k}\right)
$$

Usually $\mathrm{c} 1+\mathrm{c} 2=4$. No good reason other than empiricism. $\mathrm{V}_{\mathrm{i}}^{(\mathrm{k}+1)}$ as updated velocity of particle i leads the particle to a new position called $X_{i}^{(k+1)}$

$$
X_{i}^{k+1}=X_{i}^{k}+V_{i}^{k}
$$

$\mathrm{i}=1,2 \ldots$ nop (number of particles)

$\mathrm{k}=1,2 \ldots \mathrm{kmax}$ (maximum iteration number)

Where:

K - Iteration quantity;

i - Particle quantity;

W - Inertia weight factor;

c1 and c2 - acceleration constants;

c1 (importance of personal best)

c2 (importance of neighbourhood best)

$\mathbf{r 1}$ and $\mathbf{r 2} \quad-$ random values between 0 and 1 ;

$\mathbf{V}_{\mathbf{i}}^{\mathbf{k}} \quad$ - velocity of particle $\mathrm{i}$ at iteration $\mathrm{k}$;

$\mathbf{X}_{\mathbf{i}}^{\mathbf{k}} \quad$ - location of particle $\mathrm{i}$ at iteration $\mathrm{k}$.

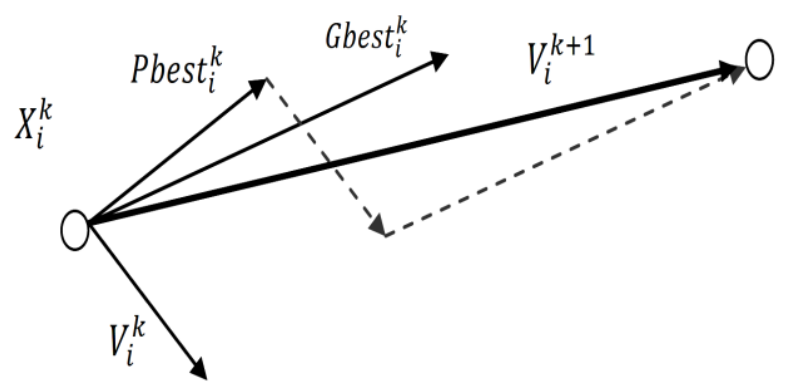

Figure 1. Simple Diagram for Movement of a Sample Particle in PSO.

Inertia weight in PSO plays a significant role because of its control on particle speed. Hence, a suitable selection of it is important. Equation (9) is the general selection of inertia weight. In current study the value of inertia weight decreases from 1.2 to 0.5 during a run time [11].

$$
\mathrm{W}=\mathrm{W}_{\max }-\left(\left(\left(\mathrm{W}_{\max }-\mathrm{W}_{\min }\right) / \text { iteration }_{\max }\right) \times \text { iteration }_{\mathrm{k}}\right)
$$

Where:

iterations

iteration $_{\max } \quad-\quad$ maximum number

iteration $_{\mathrm{k}} \quad-{ }_{\mathrm{K}}^{\text {th }}$ iteration as current iteration

\section{Disadvantages of PSO:}

Tendency to a fast and premature convergence in mid optimum points.

- Slow convergence in superior search juncture (weak local search ability)

\section{Proposed Methodology}

This paper put forward a Deterministic particle swarm optimization to improve the computational time. The main proposal is to remove the random number in the accelerations factor of the conventional PSO velocity equation [12]. Additionally, the highest change in velocity is constrained to a particular value.

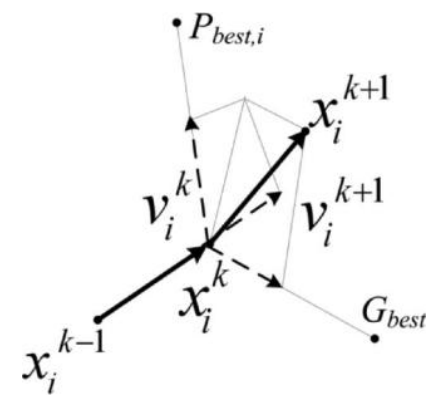

Figure 2.Movement of particles in this optimization process

The proposed approach offers several advantages:

1) Due to the absence of random values, the particles follow a deterministic behavior; for each independent run, the solution is consistent even with a small number of particles;

2) Only one parameter i.e., the inertia weight, needs to $X_{i}^{k+\text { the tuned; }}$

$X_{i}$ 3) The optimization structure is much simpler compared to conventional PSO;

$$
\begin{gathered}
v_{i}^{k+1}=w v_{i}^{k}+\left\{P_{\text {best } i}-x_{i}^{k}\right\}+\left\{G_{\text {best }}-x_{i}^{k}\right\} \\
\Downarrow \quad \text { for } 0<v<\mathrm{V}_{\max } \\
v_{i}^{k+1}=w v_{i}^{k}+\left\{G_{\text {best }}+P_{\text {best } i}-2 x_{i}^{k}\right\} .
\end{gathered}
$$

Where:

$$
\begin{array}{ll}
w & \text { - Inertia weight, } \\
\boldsymbol{P}_{\text {besti }} & \text { - Personal best position of particle i, and } \\
& \boldsymbol{G}_{\text {best }} \quad \text { - Best position of the particles. }
\end{array}
$$

The objective function is chosen to be

$$
f\left(x_{i}^{k}\right)>f\left(P_{\text {best } i}\right)
$$

of 1. RePRESEnTATION OF Swarm: Swarm is the group of particles that are moving and providing the solutions for solves a problem. The particles travel in the province of the problem space and each of them correspond to a solution for that problem. If P1, P2 and P3 are the generation units in a system, then particle $i$ flies in the 
problem area to find the best promising solution. Vector $V_{i}$ is the resultant vector which is attained from (10).

2. FITNESS FUNCTION: To estimate the proposed solutions by particles, it's necessary to identify a fitness function. The fitness function has to be able to determine which resolution is better and more competent after considering all the solutions obtained by the particles at each iteration. In general the fitness function is being set to have the lowest possible value at an optimal point.

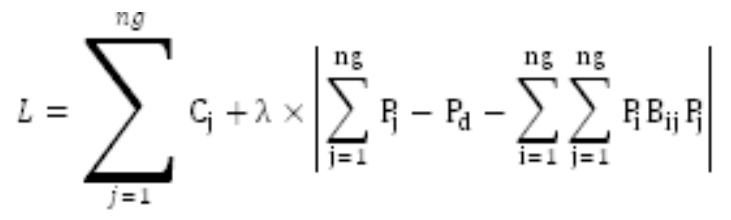

Where

L $\quad$ - Value of fitness function;

Cj - cost function of generation unit j;

Pd - power demand by the loads;

$\lambda$ - Coefficient of error;

$\mathbf{P}_{\mathbf{i}}$ and $\mathbf{P}_{\mathbf{j}}$-Generated power by $\mathrm{i}^{\text {th }}$ and $\mathrm{j}^{\text {th }}$ unit respectively

\section{PSEUdOCODE:}

FOR EACH PARTICLE

INITIALIZE PARTICLE

END

Do

FOR EACH PARTICLE

CAlCulate fitness Value

IF THE FITNESS VALUE IS BETTER THAN ITS PERONAL BEST

SET CURRENT VALUE AS THE NEW $\mathbf{P}_{\text {Best }}$

END

CHOOSE THE PARTICLE WITH THE BEST FITNESS VALUE OF ALL AS $\mathbf{G}_{\text {BEST }}$

FOR EACH PARTICLE

CALCULATE PARTICLE VElOCITY ACCORDING EQUATION

(10)

UPDATE PARTICLE POSITION ACCORDING EQUATION (8)

\section{END}

WHILE MAXIMUM ITERATIONS OR MINIMUM ERROR CRITERIA IS NOT ATTAINED

The multi-objective optimization problem is converted as single objective optimization problem by the price penalty factor of each plant can be found for a particular demand can be found as follows

1. The ratio between the average fuel cost and the average emission for maximum power capacity of that plant is found

$\mathrm{h}_{\mathrm{i}}=\mathrm{FC}_{\mathrm{i}}\left(\mathrm{P}_{\mathrm{i}}^{\max }\right) / \mathrm{EC}_{\mathrm{i}}\left(\mathrm{P}_{\mathrm{i}}^{\max }\right) \quad, \mathrm{i}=1,2, . . \mathrm{n}$
2. Based on the value of price penalty factor found the plants are arranged in ascending order.

3. The maximum capacity of each unit (Ui) is added one at a time, starting from the smallest hi unit until.

4. At this stage hi associated with the last unit in the process is the price penalty factor ' $h$ ' $(\mathrm{Rs} / \mathrm{Kg})$ for the given load demand using price penalty factor as follows Minimize $\mathrm{f}(\mathrm{FC}, \mathrm{EC})=\operatorname{Minimize}(\mathrm{FC}+\mathrm{h} . \mathrm{EC})$

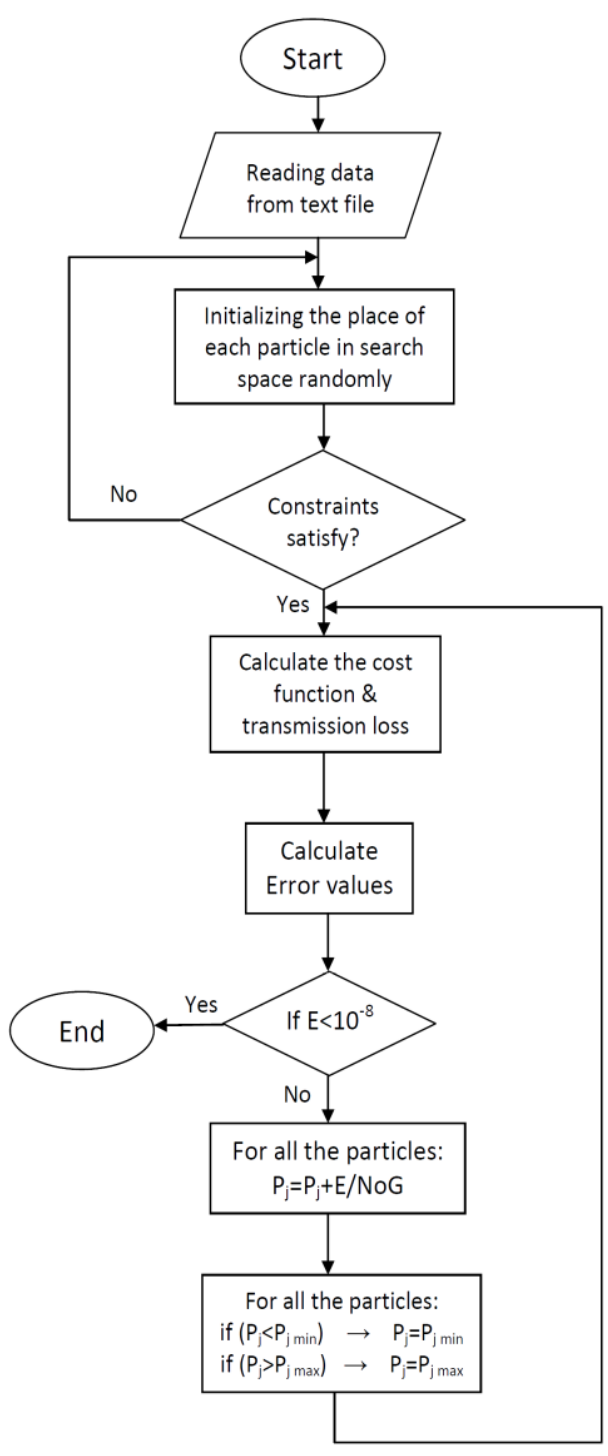

Figure 3. Flowchart for the Proposed PSO-Based Algorithm: Initializing Part.

\section{Numerical Results AND Discussion}

Here, the results of two different case studies have been brought to verify the feasibility of the proposed DPSO algorithm. In these cases, the obtained results are compared to existing MGA, PSO based results. Considering the transmission lines power losses and the transmission capacity constraints, a reasonable B loss coefficients matrix has been utilized for each case. The programming was in MATLAB coding. 
INTERNATIONAL JOURNAL OF INNOVATIVE RESEARCH IN ELECTRICAL, ELECTRONICS, INSTRUMENTATION AND CONTROL ENGINEERING

\section{CASE STUDY}

In this paper two case studies are inspect to validate the effectiveness of DPSO in optimizing economic dispatch problem. The Case- 1 applied to 3 generating system while Case 2 applied to 6 generating system.

\section{Case Study -1: Three units system}

In this a trouble-free system with three thermal units is used to make obvious how the proposed approach works. The unit uniqueness and the loss coefficients are given in Table 1.

TABLE 1

Three generating system capacity and Coefficients

\begin{tabular}{|c|c|c|c|c|c|}
\hline Unit & $\mathbf{a}_{\mathbf{i}}$ & $\mathbf{b}_{\mathbf{i}}$ & $\mathbf{c}_{\mathbf{i}}$ & $\mathbf{P}_{\mathbf{G i}}{ }^{(\mathbf{m i n})}$ & $\mathbf{P}_{\mathbf{G i}}{ }^{(\mathbf{m a x})}$ \\
\hline 1 & 0.00525 & 8.663 & 328.13 & 50 & 250 \\
\hline 2 & 0.00609 & 10.04 & 136.91 & 5 & 150 \\
\hline 3 & 0.00592 & 9.76 & 59.16 & 15 & 100 \\
\hline
\end{tabular}

Load=300MW

$$
B_{i j}=\left(\begin{array}{ccc}
0.000136 & 0.0000175 & 0.000184 \\
0.0000175 & 0.000154 & 0.000283 \\
0.000184 & 0.000283 & 0.00161
\end{array}\right)
$$

The loss coefficient matrix for three generating system is given above.It involves in finding the transmission loss by using equation (4). Table 2 offers the Emission coefficients that involved in finding the emission cost by using equation ( 3 ).

The transmission lines power losses and the transmission capacity constraints, a reasonable $\mathrm{B}$ loss coefficients matrix has been utilized for each case.

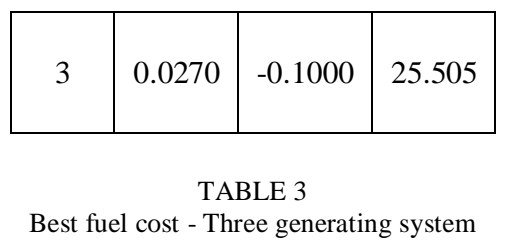

\begin{tabular}{|c|c|c|c|}
\hline Unit output & GA & PSO & DPSO \\
\hline P1(MW) & 208.99 & 123.120 & 149.892 \\
\hline P2(MW) & 86.0041 & 58.116 & 66.741 \\
\hline P3(MW) & & & \\
\hline Total generating cost $(\$ / h)$ & 3624.28 & 3616.275 & $\mathbf{3 6 1 6 . 1 6 8}$ \\
\hline Comparison of results of IEEE 14 -bus system 3 generating system & & & \\
\hline & & & \\
\hline
\end{tabular}

\begin{tabular}{|c|c|c|}
\hline Output & PSO & DPSO \\
\hline Total Emission cost(ton/h) & 0.78508 & $\mathbf{0 . 2 2 8 0 4}$ \\
\hline Transmission loss & 12.2187 & $\mathbf{1 2 . 0 9 6 5}$ \\
\hline Iteration (result converged) & 98 & $\mathbf{7}$ \\
\hline
\end{tabular}

As observe in Table 3, for the required load demand the dispatch levels of both PSO and DPSO are closer. But from table 4 it is clear that DPSO provides the best result for Multiobjective optimization with improved results compared to existing PSO.

TABLE 2

Emission Coefficients for 3 generating system

\begin{tabular}{|c|c|c|c|}
\hline Unit & $\boldsymbol{\alpha}_{\mathbf{i}}$ & $\boldsymbol{\beta}_{\mathbf{i}}$ & $\boldsymbol{\gamma}_{\mathbf{i}}$ \\
\hline 1 & 0.0126 & -1.1000 & 22.983 \\
\hline 2 & 0.0200 & -0.1000 & 22.313 \\
\hline
\end{tabular}




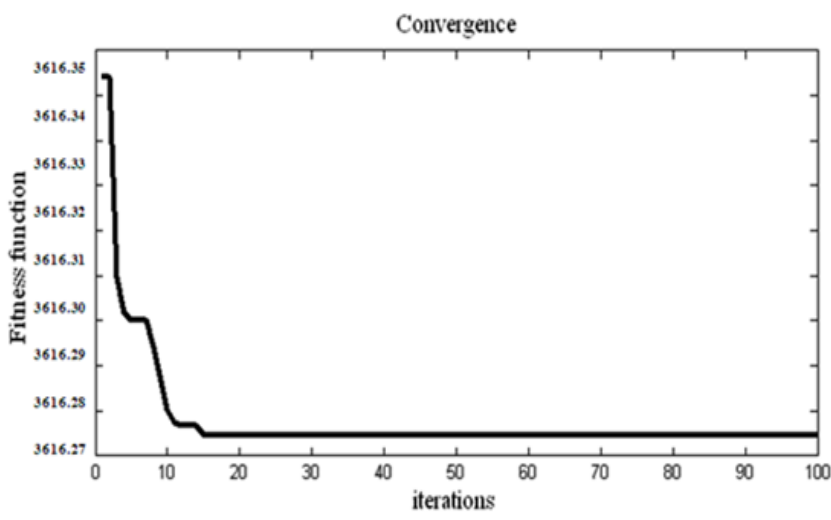

Figure 4: Convergence characteristic of Three-generator system using PSO

The variation of cost deserve $(\$ / \mathrm{h})$ against the number of iterations is shown in Fig. 4 and Fig.5 for PSO and DPSO respectively. The minimum solution is obtained within 100 iterations. From the figure 5 it was very clear that the proposed approach have better convergence efficiency than PSO, which also define that DPSO compute with reduced iteration time $(\mathrm{sec})$ compared to PSO and the fitness function obtain with reduced iterations can be found clearly in above figure 5 .

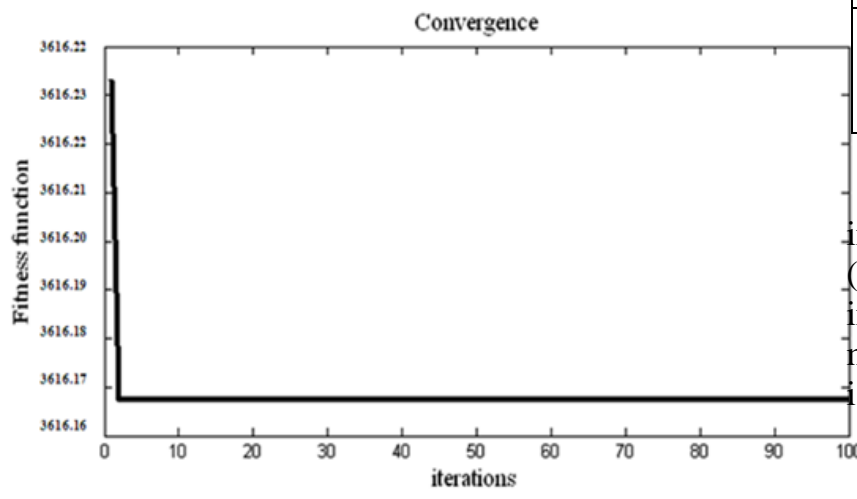

Figure 5: Convergence characteristic of Three-generator system using DPSO

The variation of cost deserve $(\$ / \mathrm{h})$ against the number of the fitness function obtain with reduced iterations can be found clearly in above figure 5. Thus Table 3,Table 4 and figure 5 shows that DPSO provides the best outcome for Multiobjective problem and has better Convergence characteristics compared to Genetic Algorithm (GA), Particle swarm optimization [2].It can be figure out that DPSO finds comparable minimum fuel cost, Emission cost, transmission loss and better computational efficiency for 3 generating unit compared to the last two evolutionary algorithms...
In this a troublesome system with six thermal units is used to make obvious how the proposed approach works. The unit coefficients and the system capacity are given in Table 5.

TABLE 5

Six generating system capacity and fuel Coefficients

\begin{tabular}{|c|c|c|c|c|c|c|c|}
\hline Unit & $\mathbf{a}_{\mathbf{i}}$ & $\mathbf{b}_{\mathbf{i}}$ & $\mathbf{c}_{\mathbf{i}}$ & $\mathbf{d}_{\mathbf{i}}$ & $\mathbf{e}_{\mathbf{i}}$ & $\mathbf{P}_{\mathbf{G i}}{ }^{(\mathbf{m i n})}$ & $\mathbf{P}_{\mathbf{G i}}{ }^{(\mathbf{m a x})}$ \\
\hline 1 & 100 & 200 & 10 & 100 & 0.084 & 0.05 & 0.05 \\
\hline 2 & 120 & 150 & 10 & 100 & 0.084 & 0.05 & 0.60 \\
\hline 3 & 40 & 180 & 20 & 100 & 0.084 & 0.05 & 1.00 \\
\hline 4 & 60 & 100 & 10 & 100 & 0.084 & 0.05 & 1.20 \\
\hline 6 & 40 & 180 & 20 & 100 & 0.084 & 0.05 & 1.00 \\
\hline 5 & 100 & 150 & 10 & 100 & 0.084 & 0.05 & 0.60 \\
\hline
\end{tabular}

Now, Table 6 offers the Emission coefficients that involved in finding the emission cost by using equation (3). In 6 generating system valve point effects [14] are included which defines that for more balanced and exact modeling of cost functions, the expression of cost function $\mathrm{s}$ to be modified suitably.

The generating units with multi-valve steam turbines exhibit a greater distinction in the cost functions. The valve opening process of multi-valve steam turbines make a ripple-like effect in the heat rate curve of the generators. The significance of this effect is that the actual cost curve function of a large steam plant is not continugus but more important it is non-linear. The valve-point effects are taken into consideration in the ED problem by superimposing the basic quadratic fuel-cost characteristics with the rectified sinusoid component.

Where $F_{T}$ is total fuel cost of generation in $(\$ / h r)$ and $E_{T}$ is total emission cost of generation in (ton/hr) including valve point loading, $\mathrm{e}_{\mathrm{i}}, \mathrm{f}_{\mathrm{i}}$ are fuel cost coefficients and $\xi_{\mathrm{i}}$, $\delta_{i}$ are emission coefficients of the $i$ th generating unit reflecting valve-point effects. 
INTERNATIONAL JOURNAL OF INNOVATIVE RESEARCH IN ELECTRICAL, ELECTRONICS, INSTRUMENTATION AND CONTROL ENGINEERING Vol. 2, Issue 10, October 2014

\begin{tabular}{|c|c|c|c|c|c|}
\hline Unit & $\boldsymbol{\alpha}_{\mathbf{i}}$ & $\boldsymbol{\beta}_{\mathbf{i}}$ & $\boldsymbol{\gamma}_{\mathbf{i}}$ & $\boldsymbol{\xi}_{\mathbf{i}}$ & $\boldsymbol{\delta}_{\mathbf{i}}$ \\
\hline 1 & 6.49 & -5.554 & 4.091 & 0.0002 & 2.857 \\
\hline 2 & 5.638 & -6.047 & 2.543 & 0.0005 & 3.333 \\
\hline 3 & 4.586 & -5.094 & 4.258 & 0.000001 & 8.000 \\
\hline 5 & 3.380 & -3.550 & 5.326 & 0.002 & 2.000 \\
\hline 6 & 5.151 & -5.555 & 6.131 & 0.00001 & 6.667 \\
\hline
\end{tabular}

\begin{tabular}{|c|c|c|c|}
\hline P6(MW) & 0.3993 & 0.3599 & 0.3415 \\
\hline Total generating cost $(\$ / \mathrm{h})$ & 608.147 & 606.6631 & $\mathbf{6 0 6 . 6 2 5 7}$ \\
\hline
\end{tabular}

TABLE 8

Comparison of results of IEEE 30-bus system 6 generating system

\begin{tabular}{|c|c|c|}
\hline Output & PSO & DPSO \\
\hline Total Emission cost(ton/h) & 0.13224 & $\mathbf{0 . 1 3 2 2 1}$ \\
\hline Transmission loss & 0.03087 & $\mathbf{0 . 0 2 8 8 6}$ \\
\hline Iteration (result converged) & 95 & $\mathbf{9}$ \\
\hline
\end{tabular}

Where $\mathrm{F}_{\mathrm{T}}$ is total fuel cost of generation in $(\$ / \mathrm{hr})$ and $\mathrm{E}_{\mathrm{T}}$ is total emission cost of generation in (ton $/ \mathrm{hr}$ ) including valve point loadil compared to PSO and the fitness function obtain with reduced iterations can be found clearly.

Loss Coefficient matrix:

\begin{tabular}{|c|c|c|c|c|c|}
\hline 0,02180 & 0.01070 & $-0,00036$ & -0.00110 & 0.00055 & 0.00330 \\
\hline 0, & 0.01704 & $-0,00010$ & -0.00179 & 0.00026 & 0.00280 \\
\hline .00040 & -0.00010 & 0.02459 & -0.01328 & -0.01180 & -0.00790 \\
\hline$-0,00110$ & -0.00179 & -0.01328 & 0.02650 & 0.00980 & 0.00450 \\
\hline 0,00055 & 0.00026 & $-0,01180$ & 0.00980 & 0.02160 & -0.00010 \\
\hline 003 & 0.00280 & $-0,00790$ & 0.00450 & -0.00010 & 0.0297 \\
\hline
\end{tabular}

TABLE 7

Best fuel cost - six generating system

\begin{tabular}{|c|c|c|c|}
\hline Unit output & NPGA & PSO & DPSO \\
\hline $\mathrm{P} 1(\mathrm{MW})$ & 0.1245 & 0.4119 & 0.1155 \\
\hline $\mathrm{P} 2(\mathrm{MW})$ & 0.2792 & 0.3219 & 0.3203 \\
\hline $\mathrm{P} 3(\mathrm{MW})$ & 0.6284 & 0.6134 & 0.6276 \\
\hline $\mathrm{P} 4(\mathrm{MW})$ & 1.0264 & 0.9309 & 0.9514 \\
\hline $\mathrm{P} 5(\mathrm{MW})$ & 0.4693 & 0.5137 & 0.5084 \\
\hline
\end{tabular}
dispatch levels of both PSO and DPSO are closer. But from table 8 it is clear that DPSO provides the best result for Multiobjective optimization with improved results compared to existing PSO.

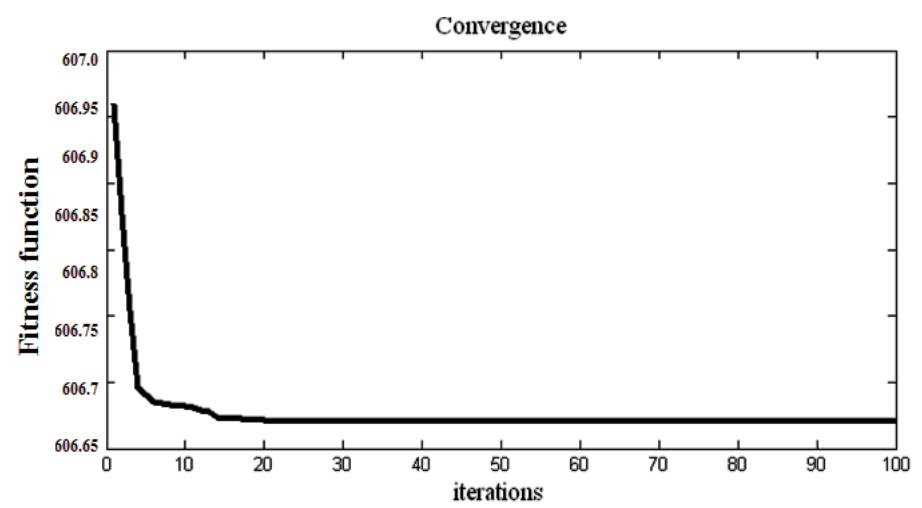

Figure 6: Convergence characteristic of six-generator system using PSO

From the figure 6 it was very clear that the PSO have inferior convergence efficiency. i.e. the fitness function can be computed with more iteration number which increases the computational efficiency of PSO. Finally it states that tendency to a fast and premature convergence in mid optimum points. Slow convergence in superior search juncture (weak local search ability) 


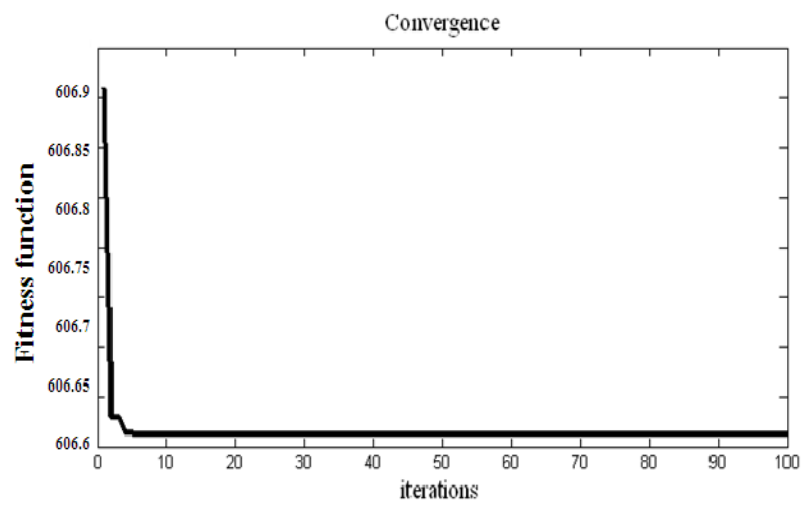

Figure 7: Convergence characteristic of six-generator system using DPSO

From the figure 7 it was very clear that the proposed approach have better convergence efficiency than PSO, which also define that DPSO compute with reduced iteration time ( $\mathrm{sec}$ ) compared to PSO. Thus Table 7, Table 8 and figure 7 shows the best cost functions and better Convergence characteristics obtained by DPSO as compared to Genetic Algorithm (GA) [13], Particle swarm optimization and the fitness function obtain with reduced iterations can be found clearly in above figure 7.It can be figure out that DPSO finds comparable minimum fuel cost and better computational efficiency compared to the last two evolutionary algorithms. Thus the stability of DPSO algorithm for this type of Multiobjective problem is verified.

\section{Conclusion}

In this paper, a new improved PSO-based algorithm is presented to solve Economic Dispatch (ED) problem. The solution process is tested on two different case studies. Results and diagrams show improvements in the quality of solution which gives a better result in terms of cost issues. This fact proves that the proposed algorithm has more ability to solve both small and large case studies compared to the existing method while the solution considers all the applied constraints of the generation units.

\section{REFERENCES}

[1] Sasikala.J,Ramaswamy.M, "Optimal $\lambda$ based Economic Dispatch using Simulated Annealing ," International journal of computer Applications (0975-8887), vol.1-No 102010.
[2] C.Kumar,T.Alwarsamy, "Solution to Economic Dispatch using Differential evoluation,"International Journal of Soft Computing and Engineering,ISSN:2231-2307,Volume-1,Issue-6,January 2012.

[3] R.Ouiddir, M. Rahli AND L. Abdelhakem-Koridak, "Economic Dispatch using a Genetic Algorithm:Application to Western Algeria's Electrical Power Network," Journal Of Information Science And Engineering 21, 659-668 (2005).

[4] Amita Mahor, Vishnu Prasad, Saroj Rangnekar," Economic dispatch using particle swarm optimization: A review", Elsevier journal,Renewable and Sustainable Energy Reviews 13 (2009) 2134-2141

[5] K. Mahadevan, P. S. Kannan and S. Kannan "Particle Swarm Optimization for Economic Dispatch of Generating Units with Valve-Point Loading" Journal of Energy \& Environment 4 (2005) $49-61$

[6] K.Senthil, K.Manikandan "Economic Thermal Power Dispatch with Emission Constraint and Valve Point Effect loading using Improved Tabu Search Algorithm", International Journal of Computer Applications (0975 - 8887)Volume 3 - No.9, July 2010

[7] Sunil Kumar Soni, Vijay Bhuria ,"Multi-objective Emission constrained Economic Power Dispatch Using Differential Evolution Algorithm.”, International Journal of Engineering and Innovative Technology (IJEIT) Volume 2, Issue 1, July 2012

[8] Robert T. F. Ah King, Harry C. S. Rughooputh and Kalyanmoy Deb.” Evolutionary Multi-Objective Environmental/Economic Dispatch: Stochastic vs. Deterministic Approaches"

[9] Rasoul Rahmani,Mohd Fouzi Othman,Rubiyah Yusof,Marzuki Khalid, "Solving Economic Dispatch Using Particle Swarm Optimization By An Solutionary Technique For Initializing Particles," journal of Theoretical and Applied Information Technology, vol.46 No.2 ,E-ISSN:1817-3195, $31^{\text {st }}$ December 2012.

[10] Jong-Bae Park, Member, IEEE, Ki-Song Lee, Joong-Rin Shin, and Kwang Y. Lee, Fellow, IEEE "A Particle Swarm Optimization for Economic Dispatch With Nonsmooth Cost Functions", IEEE TRANSACTIONS ON POWER SYSTEMS, VOL. 20, NO. 1, FEBRUARY 2005

[11] Jong-Bae Park, Member, IEEE, Yun-Won Jeong, Joong-Rin Shin, Senior Member, IEEE, and Kwang Y. Lee, Fellow, IEEE "An Improved Particle Swarm Optimization for Nonconvex Economic Dispatch Problems". IEEE TRANSACTIONS ON POWER SYSTEMS, VOL. 25, NO. 1, FEBRUARY 2010

[12] Kashif Ishaque and Zainal Salam, Member, IEEE “A Deterministic Particle Swarm Optimization Maximum Power Point Tracker for Photovoltaic System Under Partial Shading Condition". IEEE TRANSACTIONS ON INDUSTRIAL ELECTRONICS, VOL. 60, NO. 8, AUGUST 2013

[13] S. Rajasomashekar,P.Aravindhababu "Biogeography based optimization technique for best compromise solution of economic emission dispatch" elsevier journal,16 June 2012

[14] Hardiansyah "Solving Economic Dispatch Problem with ValvePoint Effect using a Modified ABC Algorithm" International Journal of Electrical and Computer Engineering (IJECE) Vol. 3, No. 3, June 2013, pp. 377 385 ISSN: 2088-8708. 